\title{
NR1H3 p.Arg415GIn Is Not Associated to Multiple Sclerosis Risk
}

\author{
Antel, Jack
}

2016-10-19

Antel , J , Ban , M , Baranzini , S, Barcellos , L, Barizzone , N, Beecham , A, Berge , T , Bernardinelli , L, Booth , D , Bos , S , Buck, D, Butkiewicz, M, Celius , E G, Comabella , M , Compston, A, Dedham , K , Cotsapas , C , Alfonso , S D , De Jager , P , Dubois , B , Duquette , P , Fontaine , B , Gasperi , C, Gil , E , Goris , A, Gourraud , P A, Graetz , C , Gyllenberg , A, Hadjigeorgiou, G, Hafler , D , Hribko , D , Haines , J , Harbo , H , Hauser , S, Warto , S, Hawkins , C, Hemmer , B , Henry , R, Hintzen, R, Horakova, D , Ivinson , A , Howard, M , Jelcic , I , Kaskow , B , Kira, J-I , Kleinova , P , Kockum , I , Kucerova , K, Palotie , A , Saarela , J \& Int Multiple Sclerosis Genetics Co 2016 , ' NR1H3 p.Arg415GIn Is Not Associated to Multiple Sclerosis Risk ', Neuron , vol. 92 , no. 2 , pp. 333-335 . https://doi.org/10.1016/j.neuron.2

http://hdl.handle.net/10138/231998

https://doi.org/10.1016/j.neuron.2016.09.052

publishedVersion

Downloaded from Helda, University of Helsinki institutional repository.

This is an electronic reprint of the original article.

This reprint may differ from the original in pagination and typographic detail.

Please cite the original version. 


\section{NR1H3 p.Arg415GIn Is Not Associated to Multiple Sclerosis Risk}

Highlights

- We attempt to replicate Wang et al.'s observation that NR1H3 p.Arg415Gln drives multiple sclerosis risk

- In a 13-fold larger sample, we find no evidence of association to either MS risk or clinical course

- We conclude their result is a false positive due to insufficient statistical rigor and flawed logic

\section{Authors}

The International Multiple Sclerosis

Genetics Consortium

Correspondence

cotsapas@broadinstitute.org

In Brief

The IMSGC find no evidence in $>69,000$ samples that NR1H3 p.Arg415GIn causes multiple sclerosis in families and determines clinical course, as reported by Wang et al. This refutes the initial claim that NR1 H3 mutations describe a Mendelian form of MS. 


\title{
NR1H3 p.Arg415GIn Is Not Associated to Multiple Sclerosis Risk
}

\author{
The International Multiple Sclerosis Genetics Consortium ${ }^{1, *}$ \\ ${ }^{1}$ Lead Contact: Chris Cotsapas \\ *Correspondence: cotsapas@broadinstitute.org \\ http://dx.doi.org/10.1016/j.neuron.2016.09.052
}

\section{SUMMARY}

A recent study by Wang et al. (2016a) claims that the low-frequency variant NR1H3 p.Arg415GIn is sufficient to cause multiple sclerosis in certain individuals and determines a patient's likelihood of primary progressive disease. We sought to replicate this finding in the International MS Genetics Consortium (IMSGC) patient collection, which is 13-fold larger than the collection of Wang et al. (2016a), but we find no evidence that this variant is associated with either MS or disease subtype. Wang et al. (2016a) also report a common variant association in the region, which we show captures the association the IMSGC reported in 2013. Therefore, we conclude that the reported low-frequency association is a false positive, likely generated by insufficient sample size. The claim of $N R 1 H 3$ mutations describing a Mendelian form of MS-of which no examples exist-can therefore not be substantiated by data. This Matters Arising paper is in response to Wang et al. (2016a), published in Neuron. See also the related Matters Arising paper by Minikel and MacArthur (2016) and the response by Wang et al. (2016b), published in this issue.

\section{INTRODUCTION}

In a recent study, Wang et al. claim an association to multiple sclerosis risk on chromosome $11 \mathrm{p} 11.2$ in the locus encoding NR1H3 (Wang et al. 2016a; Hain and Hakonarson 2016). They sequenced the exomes of two affected individuals from a multiplex family (designated MS1) and selected 37 low-frequency missense variants found in both individuals for further study. After genotyping these variants in the nine members of that pedigree-including the initial two cases-and 185 controls, they excluded 33/37 variants and then genotyped the remaining four variants in 2,053 MS patients and 799 healthy controls. They detected one variant, rs61731956 (NR1H3 p.Arg415GIn; GenBank: NM_005693.3; c.1244G>A), in a single additional case from another multiplex family (MS2), and from segregation analysis inferred that another four MS2 individuals were carriers, though only one of these has MS. Based on these four heterozygous cases, they claim linkage with a LOD score of 2.2, though the commonly accepted standard for significance is LOD $>3.0$ (Kruglyak and Lander 1995).

\section{RESULTS AND DISCUSSION}

We sought to validate the association of rs61731956 with MS susceptibility in our ongoing study of low-frequency missense variation in MS. After stringent quality control, we used linear mixed models to meta-analyze 32,852 cases and 36,538 controls of European ancestry in 14 country-level strata, genotyped for 250,000 low-frequency non-synonymous variants across all exons using Illumina's HumanCore Exome array. We detected the minor allele rs61731956-A in nine of our strata but find no evidence of association with overall MS risk (meta-analysis $\beta=0.06, p=0.32$; Table 1). As Wang et al. (2016a) report this association specifically with primary progressive MS (PPMS), we compared 1,399 PPMS cases to 13,537 relapsing remitting MS (RRMS) cases directly in six strata with available clinical course information and also find no evidence of association with disease subtype (meta-analysis $\beta=2.35, p=0.39$; Table 2 ). Our previous linkage analysis of $>700$ multiplex families (Sawcer et al. 2005) further supports this conclusion (multipoint LOD = 0.0 ), as does earlier work from the Canadian Collaborative Project on the Genetic Susceptibility to Multiple Sclerosis (CCPGSMS), with no evidence of linkage in 40 Canadian families with four or more affected individuals, authored by members of the Wang et al. (2016a) study team (Willer et al. 2007).

Based on their interpretation of segregation patterns for rs61731956, Wang et al. (2016a) go on to genotype common variants in the NR1H3 locus in 2,053 MS patients and 799 healthy controls, but fail to detect any association with overall MS risk. They then report that four of their familial cases have a clinical course consistent with that of PPMS and perform a secondary, stratified analysis of clinical course with the five tagging SNPs. They reduce their sample size to 420 PPMS and 1,287 RRMS patients for whom clinical course information was available and describe an association between rs2279238 (OR $=1.35$, $p=0.001$ ) and PPMS, but not RRMS, risk. The IMSGC has already reported a disease risk association in this region (International Multiple Sclerosis Genetics Consortium, 2013) based on $14,498 \mathrm{MS}$ cases and 24,091 controls to rs7120737, which is $420 \mathrm{~kb}$ away and in moderate LD with $r s 2279238\left(r^{2}=0.62\right.$, $\mathrm{D}^{\prime}=0.82$ between the two variants in the 1000 Genomes CEU panel; IMSGC OR $=1.10, \mathrm{p}=1 \times 10^{-9}$ for rs7120737-G). We also genotyped rs3824866, a perfect proxy for rs2279238 $\left(r^{2}=1, D^{\prime}=1\right.$ in the 1000 Genomes CEU panel), which shows 


\begin{tabular}{|c|c|c|c|c|c|c|c|c|c|c|c|c|c|}
\hline & \multicolumn{2}{|l|}{ Alleles } & \multicolumn{3}{|c|}{ Minor Allele Frequency } & \multicolumn{2}{|c|}{$\begin{array}{l}\text { Case Allele } \\
\text { Counts }\end{array}$} & \multicolumn{2}{|c|}{$\begin{array}{l}\text { Control Allele } \\
\text { Counts }\end{array}$} & \multicolumn{2}{|c|}{ Association } & \multirow[b]{2}{*}{ Cochran's Q } & \multirow[b]{2}{*}{12} \\
\hline & Minor & Major & All & Cases & Controls & A1 & A2 & $\mathrm{A} 1$ & A2 & $\mathrm{p}$ & OR & & \\
\hline Denmark & A & G & 0.00020 & 0 & 0.00040 & 0 & 2,534 & 1 & 2,475 & 0.375 & - & - & - \\
\hline Germany & A & G & 0.00025 & 0 & 0.00026 & 2 & 8,950 & 3 & 11,425 & 0.845 & - & - & - \\
\hline Italy & A & $\mathrm{G}$ & 0.00048 & 0.00065 & 0.00032 & 2 & 3,058 & 1 & 3,161 & 0.677 & - & - & - \\
\hline Netherlands & A & $\mathrm{G}$ & 0.00042 & 0.00087 & 0.00028 & 1 & 1,151 & 1 & 3,609 & 0.317 & - & - & - \\
\hline Norway & A & $\mathrm{G}$ & 0.00116 & 0.00127 & 0.00098 & 2 & 1,572 & 1 & 1,015 & 0.822 & - & - & - \\
\hline Sweden & A & G & 0.00041 & 0.00053 & 0.00027 & 7 & 13,139 & 3 & 10,989 & 0.331 & - & - & - \\
\hline UK/Austrailia & A & $\mathrm{G}$ & 0.00060 & 0.00054 & 0.00064 & 9 & 16,559 & 15 & 23,263 & 0.963 & - & - & - \\
\hline USA/Boston & A & $\mathrm{G}$ & 0.00050 & 0.00042 & 0.00060 & 5 & 11,931 & 6 & 10,046 & 0.955 & - & - & - \\
\hline USA/UCSF & A & G & 0.00048 & 0.00083 & 0.00000 & 3 & 3,627 & 0 & 2,660 & 0.127 & - & - & - \\
\hline Meta-analysis & A & G & - & - & - & 31 & - & 31 & - & 0.3293 & 1.064 & 0.825 & 0 \\
\hline
\end{tabular}

We meta-analyzed 32,852 cases and 36,538 controls of European ancestry in 14 country-level strata using linear mixed models to control for stratification. We detected the minor allele rs61731956-A in nine of our strata, but find no evidence of association to overall MS risk.

modest association to MS risk $\left(p=2.1 \times 10^{-5}\right)$. Conditioning on rs7120737 fully explains this association, indicating that the result reported by Wang et al. (2016a) is a modest proxy for the strong signal we have previously reported.

Our 13-fold larger dataset therefore supports a more conventional interpretation of the data presented by Wang et al. (2016a): there is no association between the low-frequency $\mathrm{NR} 1 \mathrm{H3}$ p.Arg415GIn variant rs61731956 and MS risk, but a common haplotype spanning the $N R 1 H 3$ locus is associated with overall MS susceptibility, despite the failure of Wang et al. (2016a) to detect it in their modestly sized cohort. Our data does not support an association specific to clinical course or PPMS. The false positive likely arose because Wang et al. (2016a) base their conclusions on a total of four affected carriers of the variant and contravene standard practice by analyzing only five polymorphisms in the NR1H3 locus, not controlling for population stratification, and failing to meet rigorous thresholds of significance for common variation $\left(\mathrm{p}<5 \times 10^{-8}\right)$ or for family-based linkage (LOD > 3) (Altshuler et al. 2008; Kruglyak and Lander 1995).

Beyond these technical issues, Wang et al. (2016a) appear to have succumbed to an error in logic in their analysis. Although individually rare, coding variants are exceedingly common in the population: of 7,404,909 variants identified by the Exome Aggregation Consortium (ExAC) in 60,706 individuals, 99\% have a minor allele frequency of $<1 \%$ and $54 \%$ are seen exactly once in those data (Exome Aggregation Consortium, 2016). Therefore, there is complete certainty of observing at least one such variant in two closely related individuals, as Wang et al. (2016a) have done. This is reinforced by their observation of rs61731956-A in multiple unaffected individuals and the presence of this variant in 21/60,706 unselected ExAC individuals. This is not a unique false positive finding, as previous studies of equivalently small sample size have reported MS risk associations to low-frequency coding variants in CYP27B1 (Ramagopalan et al. 2011) and SAIE (Surolia et al. 2010), with both results failing to replicate in much larger studies with adequate statistical power (Hunt et al. 2011; Ban et al. 2013; Barizzone et al. 2013).

We note that the experimental demonstration that p.Arg415Gln alters the heterodimerization efficiency between the NR1H3 product liver $X$ receptor alpha and the retinoid $X$ receptor alpha has no bearing on the association to MS pathogenesis. Many non-synonymous variants have dramatic effects on protein function, but in the absence of robust association to disease this alone cannot support a pathogenic argument (MacArthur et al. 2014).

The combination of our negative results from a 13-fold larger dataset and the methodological and logical flaws in the work presented by Wang et al. (2016a) categorically refute the bold claim that $\mathrm{NR} 1 \mathrm{H} 3$ variation defines a Mendelian subtype of

\begin{tabular}{|c|c|c|c|c|c|c|}
\hline & Frequency in PPMS Cases & Effect size $(\beta)$ & Standard Error & $\mathrm{p}$ & Cochran's Q & 12 \\
\hline Italy & 0 & $\mathrm{Na}$ & - & - & - & - \\
\hline Netherlands & 0 & $\mathrm{Na}$ & - & - & - & - \\
\hline Norway & 0.0013 & -0.08 & 0.19 & 0.66 & - & - \\
\hline Sweden & 0.0006 & 0.09 & 0.09 & 0.34 & - & - \\
\hline UK/Australia & 0.0007 & 0.11 & 0.11 & 0.34 & - & - \\
\hline USA/UCSF & 0.0012 & -0.08 & 0.17 & 0.65 & - & - \\
\hline Meta-analysis & - & 2.32 & - & 0.39 & 0.69 & 0 \\
\hline
\end{tabular}

We compared 1,399 PPMS cases and 13,537 RRMS cases directly in six strata with available clinical course information and also find no evidence of association between rs61731956-A and clinical subtype. 
MS, which would be the first monogenic form of the disease ever described. Such a discovery would have enormous implications for diagnosis of a subset of cases, prognosis, and genetic counselling of extended family members, and eventually for clinical management of the disease in carriers. Unfortunately, the evidence provided by Wang et al. (2016a) does not support this conclusion.

\section{SUPPLEMENTAL INFORMATION}

A list of affiliations for The International Multiple Sclerosis Genetics Consortium members is available in the Supplemental Information at http://dx.doi.org/10. 1016/j.neuron.2016.09.052.

\section{CONSORTIA}

Members of The International Multiple Sclerosis Genetics Consortium are Jack Antel, Maria Ban, Sergio Baranzini, Lisa Barcellos, Nadia Barizzone, Ashley Beecham, Tone Berge, Luisa Bernardinelli, David Booth, Steffan Bos, Dorothea Buck, Mariusz Butkiewicz, Elisabeth G. Celius, Manuel Comabella, Alastair Compston, Katrina Dedham, Chris Cotsapas, Sandra D' Alfonso, Phil De Jager, Benedicte Dubois, Pierre Duquette, Bertrand Fontaine, Christiane Gasperi, Elia Gil, An Goris, Pierre Antoine Gourraud, Christiane Graetz, Alexandra Gyllenberg, Georgios Hadjigeorgiou, David Hafler, Deanna Hribko, Jonathan Haines, Hanne Harbo, Stephen Hauser, Shannon Warto, Clive Hawkins, Bernhard Hemmer, Roland Henry, Rogier Hintzen, Dana Horakova, Adrian Ivinson, Melissa Howard, Ilijas Jelcic, Belinda Kaskow, Jun-Ichi Kira, Pavlina Kleinova, Ingrid Kockum, Karolina Kucerova, Christina M. Lill, Felix Luessi, Sunny Malhotra, Roland Martin, Filippo Martinelli, Takuya Matsushita, Cristin McCabe, Jacob McCauley, Julia Mescheriakkova, Mitja Mitrovic, Stine-Marit Moen, Xavier Montalban, Mark Muhlau, Yuri Nakmura, Jorge Oksenberg, Tomas Olsson, Annette Oturai, Aarno Palotie, Nikolaos Patsopoulos, Jana Pavlicova, Peggy Pericak-Vance, Fredrik Piehl, Isabelle Rebeix, John Rioux, Janna Saarela, Stephen Sawcer, Finn Sellebjerg, Helle Bach Sondergaard, Per Soelberg Sorensen, Mireia Sospedra, Anne Spurkland, Graeme Stewart, Bruce Taylor, Andre Uitterlinden, Cornelia Van Duijn, Frauke Zipp.

Received: June 30, 2016

Revised: September 16, 2016

Accepted: September 21, 2016

Published: October 19, 2016

\section{REFERENCES}

Altshuler, D., Daly, M.J., and Lander, E.S. (2008). Genetic mapping in human disease. Science 322, 881-888.

Ban, M., Caillier, S., Mero, I.L., Myhr, K.M., Celius, E.G., Aarseth, J., Torkildsen, Ø., Harbo, H.F., Oksenberg, J., Hauser, S.L., et al. (2013). No evidence of association between mutant alleles of the CYP27B1 gene and multiple sclerosis. Ann. Neurol. 73, 430-432.

Barizzone, N., Pauwels, I., Luciano, B., Franckaert, D., Guerini, F.R., Cosemans, L., Hilven, K., Salviati, A., Dooley, J., Danso-Abeam, D., et al.
(2013). No evidence for a role of rare CYP27B1 functional variations in multiple sclerosis. Ann. Neurol. 73, 433-437.

Exome Aggregation Consortium (2016). Analysis of protein-coding genetic variation in 60,706 humans. bioRxiv. http://dx.doi.org/10.1101/030338.

Hain, H.S., and Hakonarson, H. (2016). The Added Value of Family Material in the Discovery of Multiple Sclerosis Genes. Neuron 90, 905-906.

Hunt, K.A., Smyth, D.J., Balschun, T., Ban, M., Mistry, V., Ahmad, T., Anand, V., Barrett, J.C., Bhaw-Rosun, L., Bockett, N.A., et al.; Type 1 Diabetes Genetics Consortium; UK Inflammatory Bowel Disease (IBD) Genetics Consortium; Wellcome Trust Case Control Consortium (2011). Rare and functional SIAE variants are not associated with autoimmune disease risk in up to 66,924 individuals of European ancestry. Nat. Genet. 44, 3-5.

International Multiple Sclerosis Genetics Consortium, Beecham, A.H. Patsopoulos, N.A., Xifara, D.K., Davis, M.F., Kemppinen, A., Cotsapas, C., Shah, T.S., Spencer, C., Booth, D., Goris, A., et al.; Wellcome Trust Case Control Consortium 2 (WTCCC2); International IBD Genetics Consortium (IIBDGC) (2013). Analysis of immune-related loci identifies 48 new susceptibility variants for multiple sclerosis. Nat. Genet. 45, 1353-1360.

Kruglyak, L., and Lander, E.S. (1995). Complete multipoint sib-pair analysis of qualitative and quantitative traits. Am. J. Hum. Genet. 57, 439-454.

MacArthur, D.G., Manolio, T.A., Dimmock, D.P., Rehm, H.L., Shendure, J., Abecasis, G.R., Adams, D.R., Altman, R.B., Antonarakis, S.E., Ashley, E.A., et al. (2014). Guidelines for investigating causality of sequence variants in human disease. Nature 508, 469-476.

Minikel, E.V., and MacArthur, D.G. (2016). Publicly available data provide evidence against NR1H3 R415Q causing multiple sclerosis. Neuron 92, this issue, 336-338.

Ramagopalan, S.V., Dyment, D.A., Cader, M.Z., Morrison, K.M., Disanto, G., Morahan, J.M., Berlanga-Taylor, A.J., Handel, A., De Luca, G.C., Sadovnick, A.D., et al. (2011). Rare variants in the CYP27B1 gene are associated with multiple sclerosis. Ann. Neurol. 70, 881-886.

Sawcer, S., Ban, M., Maranian, M., Yeo, T.W., Compston, A., Kirby, A., Daly, M.J., De Jager, P.L., Walsh, E., Lander, E.S., et al.; International Multiple Sclerosis Genetics Consortium (2005). A high-density screen for linkage in multiple sclerosis. Am. J. Hum. Genet. 77, 454-467.

Surolia, I., Pirnie, S.P., Chellappa, V., Taylor, K.N., Cariappa, A., Moya, J., Liu, H., Bell, D.W., Driscoll, D.R., Diederichs, S., et al. (2010). Functionally defective germline variants of sialic acid acetylesterase in autoimmunity. Nature 466 , 243-247.

Wang, Z., Sadovnick, A.D., Traboulsee, A.L., Ross, J.P., Bernales, C.Q., Encarnacion, M., Yee, I.M., de Lemos, M., Greenwood, T., Lee, J.D., et al. (2016a). Nuclear Receptor NR1H3 in Familial Multiple Sclerosis. Neuron 90, 948-954.

Wang, Z., Sadovnick, A.D., Traboulsee, A.L., Ross, J.P., Bernales, C.Q., Encarnacion, M., Yee, I.M., de Lemos, M., Greenwood, T., Lee, J.D., et al. (2016b). Case-control studies are not familial studies. Neuron 92, this issue, 339-341.

Willer, C.J., Dyment, D.A., Cherny, S., Ramagopalan, S.V., Herrera, B.M., Morrison, K.M., Sadovnick, A.D., Risch, N.J., and Ebers, G.C. (2007). A genome-wide scan in forty large pedigrees with multiple sclerosis. J. Hum. Genet. 52, 955-962. 